\title{
Treatment and prognosis of non-specific genital infection
}

\author{
B. A. EVANS
}

From the Department of Genitourinary Medicine, West London Hospital

SUMMARY In a comparative trial minocycline was the best oral tetracycline compound for twicedaily administration in the treatment of non-specific urethritis. A review six months later showed that $29 \%$ of patients had needed further treatment, $35 \%$ of these more than one month after initial treatment and $12 \%$ between three and six months later. The history revealed no evidence of predisposition to non-specific urethritis among patients in whom relapse occurred. Multiple relapses were in the groups of patients who relapsed earliest. These cases proved more resistant to subsequent treatment, but all patients were eventually cured. The records of female contacts showed that $29 \%$ were symptomatic, $44 \%$ had an abnormal appearance of the cervix, but only $11 \%$ had inflammatory changes detected on cytological smear. A previous report was confirmed that there was no apparent benefit from the empirical treatment of contacts; possible reasons for this are given.

\section{Introduction}

The cure rate for non-specific urethritis (NSU) is consistently lower than that for most other sexually transmitted diseases of known aetiology. In this trial two drugs which have been reported to be particularly effective are compared with low-dose oxytetracycline (250 $\mathrm{mg}$ twice daily). Minocycline (Minocin), $200 \mathrm{mg}$ immediately and $100 \mathrm{mg}$ twice daily for seven days, was found to have a threemonth retreatment rate of $10.4 \%$ (Willcox et al., 1975), and sustained-release oral tetracycline (Tetrabid-Organon), $500 \mathrm{mg}$ immediately and $250 \mathrm{mg}$ twice daily for seven days, is recorded as having a $1.3 \%$ failure rate four weeks after treatment (Perera, 1975).

A previous finding that as many as $10(13 \%)$ out of 76 relapses occurred during the third month after treatment (Evans, 1977) led to the patients in the present trial being assessed after three months and again after six months, and also to multiple relapses being recorded. The value of empirical treatment of contacts has been re-examined, and the clinical and laboratory findings have been analysed in relation to relapse of urethritis.

\footnotetext{
Address for reprints: B. A. Evans, Department of Genitourinary Medicine, West London Hospital, Hammersmith Road, London W6 7DQ

Received for publication 8 September 1977
}

\section{Material and methods}

This investigation was on 505 patients who attended between April and October 1976. Patients who had been treated for NSU during the previous 12 months were excluded, as were those who had been given antibiotics during the previous three months. Diagnosis of, or contact with, any other sexually transmissible disease also resulted in the patient being excluded from the trial, as did a history of tetracycline allergy.

Patients were allocated one of three treatments according to a prepared randomisation chart; this treatment remained unknown to the investigator until the outcome had been assessed. The regimens were oxytetracycline $250 \mathrm{mg}$ twice daily, sustained release tetracycline (Tetrabid-Organon) one $250 \mathrm{mg}$ capsule twice daily, and minocycline (Minocin) $100 \mathrm{mg}$ twice daily; each was taken for seven days. Attendance for assessment was requested two weeks and four weeks after the start of treatment. The patients' documents were reviewed at three and six months.

Gram-stained smears of urethral exudate were examined with a $\times 100$ oil immersion objective lens, and the diagnosis of NSU was made if there were more than 10 polymorphonuclear leucocytes (PMN) in five microscope fields. Additional routine investigations were culture of urethral exudate for 
Neisseria gonorrhoeae and macroscopic examination of the first flush urine for urethral threads. Patients were regarded as cured if their urethral smear was normal after at least two hours' continence of urine. The outcome was assessed after three months and then again after six months from the start of treatment. Statistical significance was calculated by the $\chi^{2}$ test. Contact slips were issued for the attendance of sexual partners.

\section{Results}

The 505 patients were aged between 16 and 62 years (mean 28$) ; 23(4.6 \%)$ were homosexual. Sixty-two patients $(12 \%)$ were withdrawn from the trial for reasons that included gonorrhoea (seven cases), contact with trichomoniasis (five cases), and treponemal infection (11 cases, three of which were early syphilis). In most of the remainder the protocol had been ignored; 15 patients had been treated for NSU within the previous year and $129(25 \%)$ patients did not complete two weeks' observation; so the result of treatment could be adequately assessed in only 314 patients. Table 1 gives an analysis of these results three months after treatment. A further 15

Table 1 Outcome of trial at three months

\begin{tabular}{|c|c|c|c|c|c|}
\hline \multirow[b]{2}{*}{ Outcome } & \multicolumn{3}{|l|}{ Drug group } & \multicolumn{2}{|c|}{ Total patients } \\
\hline & $\begin{array}{l}\text { Oxytetra- } \\
\text { cycline* }\end{array}$ & $\begin{array}{l}\text { Tetra- } \\
\text { cycline } \dagger\end{array}$ & $\begin{array}{l}\text { Mino- } \\
\text { cycline }\end{array}$ & No. & $\%$ \\
\hline $\begin{array}{l}\text { Removed } \\
\text { Defaulted } \\
\text { Cured } \\
\text { Relapsed } \\
\text { Total }\end{array}$ & $\begin{array}{c}19 \\
41 \\
67 \\
42(28 \%) \\
169\end{array}$ & $\begin{array}{l}24 \\
40 \\
60 \\
43(30 \%) \\
167\end{array}$ & $\begin{array}{l}19 \\
48 \\
73 \\
29(19 \%) \\
169\end{array}$ & $\begin{array}{l}62 \\
129 \\
200 \\
114(26 \%) \\
505\end{array}$ & $\begin{array}{l}12 \\
25 \\
40 \\
23\end{array}$ \\
\hline
\end{tabular}

patients relapsed during the next three months, but these have been omitted so that the results may be compared with a previous report (Evans, 1977) in which two other tetracycline compounds were compared with low-dose oxytetracycline and no difference in cure rate was found. In the present trial, minocycline produced the best results, with only 29 patients $(19 \%)$ requiring further treatment during the next three months. During this period, 42 patients $(28 \%)$ who received low-dose oxytetracycline and 43 patients $(30 \%)$ who received sustainedrelease tetracycline required further treatment. Minocycline had approximately half the relapse rate of the other two tetracyclines during the period from two to four weeks after treatment when most relapses occur $\left(\chi_{2}{ }^{2}=5 \cdot 857,0 \cdot 1>P>0.05\right)$, but thereafter there was little difference in the relapse rates with the three drugs (Table 2).

After six months' observation $129(29 \%)$ patients had relapsed, but $55(12 \%)$ of them relapsed on more than one occasion (Figure). There was no difference between the three treatment groups in this respect (Table 3). Subsequent treatment did not form part of the trial, but it was found that between $36 \%$ and $63 \%$ (mean $44 \%$ ) of those who required further treatment had another relapse (Table 3). A history of NSU more than one year previously was given by 78 patients who were adequately assessed, and of these 43 were cured ( $23 \%$ of total cured) and 35 relapsed $(27 \%$ of total who had relapses). Previous NSU did not correlate with unsuccessful treatment, and it did not correlate with repeated relapse (Table 4).

Patients for whom contacts had attended were grouped according to their own responses to treatment (Table 5). This shows no significant difference between the relapse and no relapse groups $\left(\chi_{1}^{2}=\right.$ $0.281, P>0.5)$, and confirms the findings of an earlier paper (Evans, 1977).

Sixty-six female contacts of 64 patients attended and their clinical and laboratory findings are

Table 2 Relapse of NSU during six months' observation

\begin{tabular}{|c|c|c|c|c|c|}
\hline \multirow{2}{*}{$\begin{array}{l}\text { Period } \\
\text { between } \\
\text { treatment } \\
\text { and relapse } \\
\text { (weeks) }\end{array}$} & \multicolumn{3}{|c|}{ Drug group } & \multicolumn{2}{|c|}{ Total patients } \\
\hline & $\begin{array}{l}\text { Oxytetra- } \\
\text { cycline* }\end{array}$ & $\begin{array}{l}\text { Tetra- } \\
\text { cycline } \dagger\end{array}$ & $\begin{array}{l}\text { Mino- } \\
\text { cycline }\end{array}$ & No. & $\%$ \\
\hline $2-4$ & $36(5)$ & $30(7)$ & $18(1)$ & 84 & 65 \\
\hline $5-13$ & $6(1)$ & 13 & 11 & 30 & 23 \\
\hline $14-26$ & 7 & 3 & 5 & 15 & 12 \\
\hline Total & 49 & 46 & 34 & 129 & \\
\hline
\end{tabular}

Asymptomatic relapse shown in brackets

*Low-dose †Sustained-release

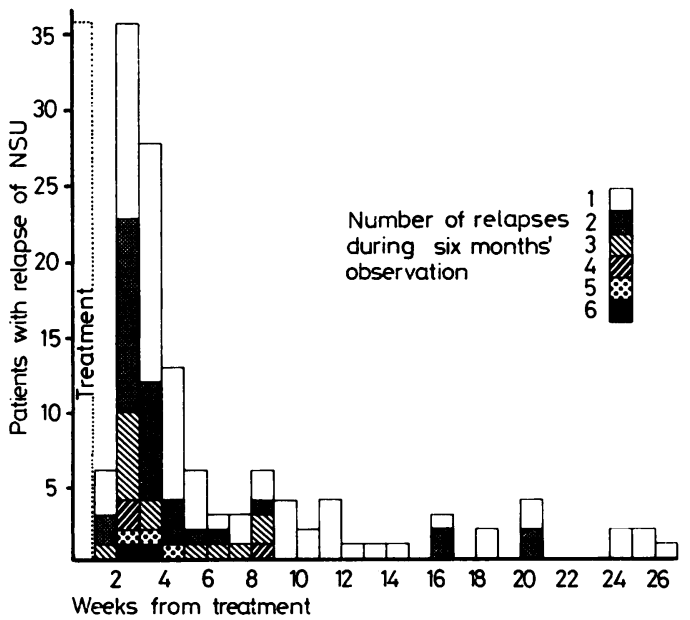

Figure Interval between initial treatment of NSU and diagnosis of relapse with infilling to show number of relapses during six months' observation 
Table 3 Number of relapses during six months' observation

\begin{tabular}{|c|c|c|c|c|c|}
\hline \multirow[b]{2}{*}{$\begin{array}{l}\text { No. of } \\
\text { relapses }\end{array}$} & \multicolumn{3}{|l|}{ Drug group } & \multirow{2}{*}{$\begin{array}{l}\begin{array}{l}\text { Total } \\
\text { patients }\end{array} \\
\text { No. }\left({ }_{0}^{\circ}\right)\end{array}$} & \multirow{2}{*}{$\begin{array}{l}\text { Relapse } \\
\text { rate } \\
\text { at each } \\
\text { relapse } \\
\%\end{array}$} \\
\hline & $\begin{array}{l}\text { Oxytetra- } \\
\text { cycline }\end{array}$ & $\begin{array}{l}\text { Tetra- } \\
\text { cycline } \dagger\end{array}$ & $\begin{array}{l}\text { Mino- } \\
\text { cycline }\end{array}$ & & \\
\hline 1 & 24 & 29 & 21 & $74(57 \cdot 5)$ & 43 \\
\hline 2 & 16 & 10 & 7 & 33 (26) & 40 \\
\hline 3 & 6 & 5 & 3 & 14 (11) & 36 \\
\hline 4 & 1 & 1 & 1 & 3 (2) & 63 \\
\hline 5 & 2 & 0 & 1 & $3(2)$ & 40 \\
\hline 6 & 0 & 1 & 1 & $2(1 \cdot 5)$ & \\
\hline Total & 49 & 46 & 34 & 129 & \\
\hline
\end{tabular}

*Low-dose +Sustained-release

Table 4 Relapsing patients with a history of NSU

\begin{tabular}{|c|c|c|c|c|}
\hline \multirow[b]{2}{*}{ No. of relapses } & \multicolumn{3}{|l|}{ Drug group } & \multirow{2}{*}{$\begin{array}{l}\begin{array}{l}\text { Total } \\
\text { patients }\end{array} \\
\text { No. }\left({ }^{\circ}\right)\end{array}$} \\
\hline & $\begin{array}{l}\text { Oxytetra- } \\
\text { cycline* }\end{array}$ & $\begin{array}{l}\text { Tetra- } \\
\text { cycline } \dagger\end{array}$ & $\begin{array}{l}\text { Mino- } \\
\text { cycline }\end{array}$ & \\
\hline 1 & 8 & 9 & 9 & $26(74)$ \\
\hline 2 & 3 & 0 & 1 & $4(11 \cdot 5)$ \\
\hline 3 & 2 & 2 & 0 & $4(11 \cdot 5)$ \\
\hline 4 & 0 & 0 & 0 & 0 \\
\hline 5 & 0 & 0 & 0 & 0 \\
\hline 6 & 0 & 0 & 1 & $1(3)$ \\
\hline Total & 13 & 11 & 11 & 35 \\
\hline
\end{tabular}

*Low-dose †Sustained-release

Table 5 Treatment of contacts of patients with NSU

\begin{tabular}{|c|c|c|c|c|c|}
\hline \multirow[b]{2}{*}{$\begin{array}{l}\text { Patients with } \\
N S U\end{array}$} & \multicolumn{3}{|c|}{ Relapse (weeks) } & \multirow{2}{*}{$\frac{\text { No relapse }}{\text { No. }}$} & \multirow{2}{*}{$\frac{\text { Total }}{\text { No. }}$} \\
\hline & $2-4$ & $5-13$ & $14-26$ & & \\
\hline Total & 84 & 30 & 15 & 185 & 314 \\
\hline $\begin{array}{l}\text { No. with a } \\
\text { treated } \\
\text { contact }\end{array}$ & $22\left(25^{0}, 0\right)$ & $4\left(13^{\circ}{ }_{11}\right)$ & $3\left(20_{0}^{\circ}\right)$ & $35\left(19^{\circ}{ }_{0}\right)$ & $64\left(20_{0}^{\circ}\right)$ \\
\hline $\begin{array}{c}\text { Delay before } \\
\text { treatment } \\
\text { (days) } \\
\text { Mean } \\
\text { Range }\end{array}$ & $\begin{array}{r}4.7 \\
0-25\end{array}$ & $\begin{array}{l}4 \cdot 5 \\
1-14\end{array}$ & $\begin{array}{l}3 \cdot 3 \\
1-6\end{array}$ & $\begin{array}{l}3 \cdot 2 \\
0-13\end{array}$ & \\
\hline
\end{tabular}

summarised in Table 6. They are divided into two groups according to whether the patient with whom they were in contact relapsed after treatment or remained cured during the six-month period of observation. This was done on the principle that if a sexually transmitted organism is the cause of the disease, the contact of a patient in whom treatment proves unsuccessful is more likely to be infected than the contact of a patient who is cured. The groups were similar in respect of number of symptoms, contraception, appearance of cervix, purulence of cervical mucus under a microscope, and cervical cytology. The low incidence of inflam-
Table 6 Clinical and laboratory findings in 66 female contacts of NSU

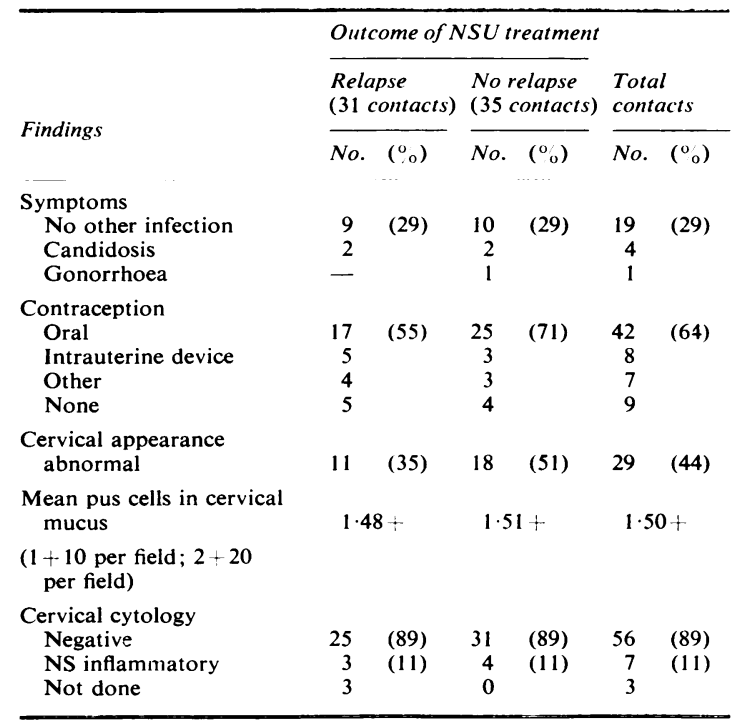

matory changes in the cytological smears $(11 \%)$ suggests that any micro-organism has little cytopathic effect.

\section{Discussion}

The value of a comparative trial is illustrated by the relapse rate for low-dose oxytetracycline in this trial compared with that reported previously (Evans, 1977). The corresponding figures are $19 \%$ for the trial carried out previously (Evans, 1977) and $28 \%$ for this. These figures illustrate the futility of comparing results obtained in trials undertaken on different populations at different times without the incorporation of a drug common to both trials. In this instance it is possible to compare the present results with those reported last year. The combined trials show that sustained-release tetracyclines (Sustamycin and Tetrabid-Organon) and triple tetracycline (Deteclo) have no advantage over low-dose oxytetracycline ( $250 \mathrm{mg}$ twice daily) in the treatment of NSU, but that minocycline (Minocin) offers a better cure rate. This effect was manifest by a lower relapse rate during the month after treatment (Table 2), and may be attributable to its greater lipophilicity facilitating higher tissue levels of the antibiotic (Macdonald et al., 1973). However, it did not produce a lower relapse rate than low-dose oxytetracycline in the first trial. Thus, there seems to be a limiting cure rate of about $85 \%$, which no antibiotic regimen can better, and it has been 
suggested previously that psychological factors predetermine this phenomenon.

By extending the period of review from three to six months the number of patients who relapsed increased by $13 \%$. Multiple relapses occurred among those patients who relapsed earliest (Figure) but all patients had been cured by the end of six months. During this time two patients were each treated for six relapses. Initial treatment proved the most successful with a relapse rate of $23 \%$ during the first two months, when $93 \%$ of those patients who relapsed repeatedly required further treatment. Subsequent treatment with a variety of regimens showed failure rates of between $36 \%$ and $63 \%$ (Table 3), twice that of initial treatment. Moreover, these patients received courses of treatment for up to three weeks. While this confirms the clinical impression that failure of first treatment carries an unfavourable prognosis, it also shows that the condition ultimately resolves. The findings also fail to support the view that some patients have an inherent susceptibility to NSU, since those with a past history were proportionately distributed between cured and relapsed groups.

Analysis of empirical treatment of contacts confirmed the previously reported conclusion (Evans, 1977) that neither partner appeared to benefit (Table 5), and that the relapse rate was as high among patients whose contacts were treated as among those whose contacts were not. It is conceivable that failure was caused by the contact not complying with the treatment and thus remaining 'infected' with a causal agent of NSU. Scrutiny of various clinical and laboratory findings may therefore reveal some difference in these contacts compared with those of patients who did not relapse, since this group would include contacts who were 'uninfected' before treatment. Table 6 shows that the groups did not differ in any marked way.

Findings among the 66 female contacts of patients with NSU for whom follow-up was satisfactory show some interesting results in a group little studied in the past. Symptoms were present in $29 \%$ of those in whom no other infection (that is, candidal, trichomonal, or gonococcal) was detected. The symptoms comprised vaginal discharge, pruritus vulvae, and dysuria, but mostly of mild degree, as might be anticipated in patients who did not present spontaneously but had been requested to attend for examination. It is difficult to draw conclusions from this finding in the absence of a control group similarly summoned for examination but in the proved absence of any disease in their sexual contacts. The abnormal appearance of the cervix noted in $44 \%$ was described as either 'erosion' or cervicitis, terms which vary widely in their application, and this is also impossible to interpret without a control group. However a more recent sample of patients who were contacts of NSU was compared with a sample who had neither past nor present infection. This showed that an abnormal cervical appearance was found in $50 \%$ of the NSU contact group and in $56 \%$ of the control group (unpublished observations). Cervical secretions containing 10-20 pus cells per field might be considered within the range of normal variability in young sexually active women, $76 \%$ of whom are either taking an oral contraceptive or fitted with an intrauterine device. Furthermore, only $11 \%$ of the $95 \%$ of NSU contacts tested showed inflammatory changes in the epithelial cells on routine cervical cytological smear; $89 \%$ proved to have normal smears. Therefore, neither of these methods seems of any value in assessing the presence of infection in NSU contacts. Previous work has shown that $76 \%$ of contacts of gonorrhoea attending for examination are, in fact, infected (Evans, 1976) so that a figure of only $11 \%$ seems improbable in contacts of NSU.

The insuperable failure rate of NSU treatment may well be determined by a number of essentially psychological factors. Preoccupation with a previously ignored but sexually significant site, leading to excessive self-examination and therefore continual physical irritation, is well known to venereologists; these patients are sometimes referred to as 'squeezers'. That this phenomenon should occur in NSU but not in gonorrhoea can be explained by the more gradual onset and slower response to treatment characteristic of NSU, leaving the patient with a longer period in which to develop the habit. Disregard of other aggravating factors such as continued sexual intercourse and alcohol consumption may also lead to relapse.

One explanation for these findings is that the man may acquire sufficient local immunity after adequate treatment of his initial infection to be able to resist reinfection for several weeks, during which time the infecting agent can be eliminated spontaneously by the woman in whom it appears to be of low pathogenicity. Thus, early relapses are caused by inadequate resolution of the original urethritis and later relapses by reinfection. This is supported by the isolation of Chlamydia trachomatis only in patients in whom relapse occurred more than six weeks after treatment (Handsfield et al., 1976), and by the finding that only $15 \%$ of patients who relapsed within four weeks of treatment gave a history of re-exposure (Evans, 1977). It is also consistent with the present finding that minocycline reduces the incidence of early relapse but not the incidence of late relapse, since it would not be expected to protect against reinfection. 
I should like to thank Mr James Bennett, SRN, $\mathrm{RMN}$ and his colleagues for invaluable help in the conduct of the trial, and the Department of Medical Illustration, Charing Cross Hospital, for the Figure.

\section{References}

Evans, B. A. (1976). Detection of gonorrhoea in women. British Journal of Venereal Diseases, 52, 40-42.

Evans, B. A. (1977). The role of tetracyclines in the treatment of non-specific urethritis. British Journal of Venereal Diseases, 53, 40-43.
Handsfield, H. H., Alexander, E. R., Pin Wang, S., Pederson, A. H. B. and Holmes, K. K. (1976). Differences in the therapeutic response of chlamydia-positive and chlamydia-negative forms of nongonococcal urethritis. Journal of the American Venereal Disease Association, 2, 5-9.

Macdonald, H., Kelly, R. G., Allen, E. S., Noble, J. F., and Kanegis, L. A. (1973). Pharmacokinetic studies on minocycline in man. Clinical Pharmacology and Therapeutics, 14, 852-861.

Perera, P. M. (1975). Evaluation of a sustained-release oral tetracycline in non-specific urethritis. British Journal of Venereal Diseases, 51 , 333-335.

Willcox, R. R., Sparrow, R. W., and Fazluddin, C. M. (1975). Minocycline in the treatment of non-gonococcal urethritis. British Journal of Venereal Diseases, 51, 206-209. 